\title{
SISTEM PRESENSI BERBASIS FACE RECOGNITION
}

\author{
Habiburrahman ${ }^{1}$, Ichsan Kurniawan², Tri Irfan ${ }^{3}$ \\ ${ }^{124}$ Program Studi Elektronika Industri, Jurusan Teknik Elektro, Politeknik Negeri Jakarta, Jl. Prof. Dr. G.A Siwabessy, \\ Kampus Baru UI, Depok, 16424, Indonesia
}

Diterima : 20 Agustus 2019. Disetujui : 20 September 2019. Diterbitkan: Oktober 2019

\begin{abstract}
Face Recognition is one of the biometric techniques in the field of computer vision that enables computers or authentic machines to recognize human faces. Face recognition is carried out with image processing techniques through a complex array of algorithms. This process provides movement to the computer to detect and recognize certain objects. The presence system using face recognition techniques is expected to be able to produce better output than using other recognition techniques. Done by integrating the OpenCV library on the Linux operating system using the MiniPC Z85 Series as the main data processor system. Programming image processing for face recognition on the system is written using the python programming language that is run on a linux terminal and uses a Logitech C525 camera in image processing. The process consists of 2 stages, first the training process is carried out by taking 40 face samples that produce the highest accuracy in identifying faces at the time of testing. The second stage, recognition of the face is influenced by several factors such as distance and light. The test results obtained the best distance between a webcam with a face is $30-59 \mathrm{~cm}$ with a light intensity of 800-999 Lux.
\end{abstract}

Key words: face recognition, image processing, presence system, miniPC, logitech camera, python.

\section{ABSTRAK}

Face Recogntion merupakan salah satu teknik biometrik bidang visi komputer yang memungkinkan komputer atau mesin autentik untuk mengenal wajah manusia. Face recogntion dilakukan dengan teknik pengolahan citra (image processing) melalui rangkain algoritma yang kompleks. Proses ini memberikan gerakan pada komputer untuk mendeteksi dan mengenali objek tertentu. Sistem Presensi menggunakan teknik pengenalan wajah diharapkan mampu mengasilkan output yang lebih baik dibandingkan menggunakan teknik pengenalan lainnya. Dilakukan dengan mengintegrasikan library OpenCV pada sistem operasi linux menggunakan MiniPC Z85 Series sebagai pengolah data utama sistem. Pemrograman image processing untuk face recognition pada sistem ditulis dengan menggunakan bahasa pemrograman python yang dijalankan pada terminal linux dan menggunakan kamera logitech C525 pada proses pengolahan citra. Proses terdiri dari 2 tahapan, pertama proses training dilakukan dengan mengambil 40 sampel wajah yang menghasilkan akurasi paling tinggi dalam mengidentifikasi wajah pada saat pengujian. Tahap yang kedua, pengenalan pada wajah yang dipengaruhi oleh bebeapa faktor seperti jarak dan cahaya. Hasil pengujian diperoleh jarak terbaik antara webcam dengan wajah adalah $30-59 \mathrm{~cm}$ dengan intensitas cahaya 800-999 Lux

Kata kunci: face recognition, image processing, sistem presensi, miniPC, kamera logitech, python.

\section{PENDAHULUAN}

Sistem presensi adalah hal yang penting dalam kehidupan sehari hari sebagai salah satu cara pencatat kehadiran seseorang baik pada lingkup tempat kerja, sekolah, maupun kampus. Di kampus Politeknik Negeri Jakarta sistem absensi masih dilakukan secara manual dengan cara melakukan absen terhadap setiap mahasiswa pada lembar kertas absensi. Hal itu tentu kurang efisien karena terbukanya kesempatan untuk melakukan kecurangan seperti pemalsuan data ataupun kesalahan dalam menuliskan kehadiran mahasiswa (Human Error). Selain itu, rekapitulasi oleh administrasi juga dilakukan dengan cara manual yang membutuhkan waktu lama karena 
harus memasukkan banyak data. Dengan semakin berkembangnya bidang teknologi, saat ini telah banyak dibangun sistem presensi dengan pengenalan pola yang mengenali ciriciri khusus fisik manusia diantaranya pengenalan wajah dan pengenalan sidik jari. Dengan memanfaatkan pola ciri-ciri khusus fisik tersebut, sehingga dapat meminimalisir kecurangan yang terjadi saat proses absensi.

Sistem pengenalan ciri-ciri khusus fisik menggunakan sidik jari merupakan sistem yang paling banyak digunakan pada saat ini. Selain karena murah dan banyak tersedia dipasaran, proses pengolahan data ke database relatif mudah. Namun pengenalan dengan menggunakan sidik jari memiliki beberapa kekurangan yang cukup signifikan dalam mempengaruhi keluaran pada sistem, seperti tidak dapat mengidentifikasi data sidik jari yang sudah terdaftar, yang disebabkan oleh tangan yang basah atau kotor, pembengakakan jari, dan cacat pada sidik jari (Abdul Malik, 2015). Maka dari itu, mengidentifikasi melalui pola ciri-ciri khusus fisik pengenalan wajah merupakan cara untuk mengatasi kekurangan pada sistem presensi menggunakan pengenalan dengan sidik jari.

\section{METODE PENELITIAN}

Principal Component Analysis (PCA) berdasar pada konsep konsep teori informasi, PCA ini sangat mudah digunakan di dalam OpenCV. PCA mencari sebuah model berbasis komputer yang menggambarkan sebuah wajah dengan mengambil keterangan-keterangan yang penting dari sebuah gambar. PCA memiliki beberapa keunggulan yaitu dapat bekerja secara cepat dan membutuhkan jumlah memori yang kecil. Eigenface merupakan salah satu contoh dari metode PCA.

Dalam algortima Eigenface, jika dimisalkan dalam suatu sistem sudah ada database yang berisi gambar-gambar dari orang yang dikenali, kemudian sistem diberikan gambar orang yang tidak dikenali maka secara umum berikut adalah langkah atau prosedur sebuah wajah terdeteksi:
- Menghitung jarak dari gambar tersebut dibandingkan dengan gambar-gambar yang ada di dalam database.

- Memilih sebuah gambar dari database yang mendekati wajah yang ada di dalam gambar tersebut.

- Jika jarak yang telah diukur tersebut hasilnya diatas nilai dari threshold maka gambar tersebut dikenali oleh sistem, tetapi bila nilai yang dihasilkan lebih kecil maka gambar tersebut termasuk dalam gambar yang tidak dikenali oleh sistem karena sistem hanya mengenali gambar yang ada di dalam database.

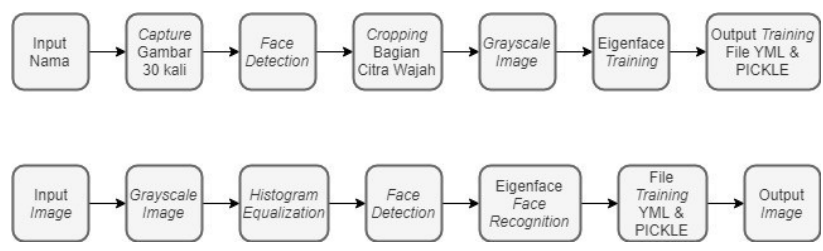

Gambar 1 Diagram Blok Face Recognition Sistem

Data dari karakteristik Image Prcessing yang didapat dari pengukuran alat-alat berikut :

1. Mini PC Z85

Untuk mengolah data keseluruhan sistem Face Recognition. Alat ini menggunakan supply $12 \mathrm{~V}$ dan keluaran dari alat ini berupa port USB $5 \mathrm{~V}$.
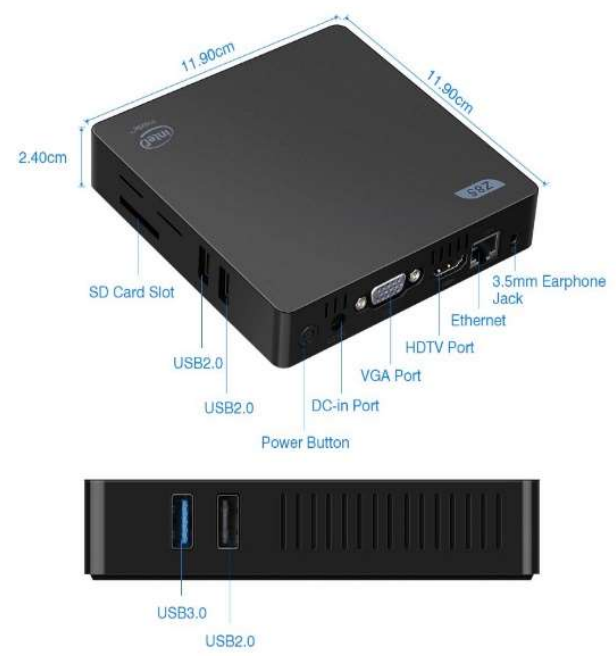

Gambar 2 MiniPC Z85 
2. Webcam Logitech C525

Dalam pengukuran alat ini, output pengambilan gambar wajah sebanyak 40 kali dalam sekali perekaman. Alat ini juga menggunakan supply $5 \mathrm{~V}$ dan keluaran dari alat ini yaitu pengambilan gambar wajah.

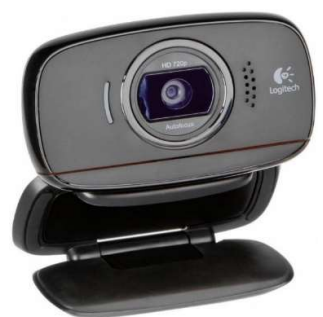

Gambar 3 Webcam Logitech C525

3. Intensitas Cahaya(Lux Meter)

Alat untuk mengukur intensitas cahaya. Kami hanya menggunakan 1 parameter saja $y$ intensitas cahaya. Sensor ini juga menggunakan supply $5 \mathrm{~V}$

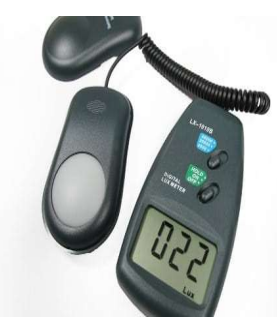

Gambar 4 Lux Meter

\section{Rol Meter}

Alat ini digunakan dalam mengukur jarak antara pengguna dengan alat untuk Face Recognition.

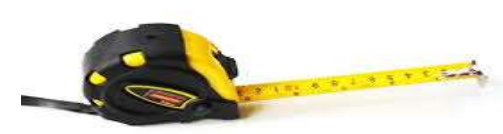

Gambar 5 Rol Meter

Proses realisasi pemrograman untuk sistem pengenalan wajah dilakukan dengan mengintegrasikan OpenCV dengan sistem operasi Linux pada MiniPC Z-8350 yang ditulis dengan bahasa pemrograman python. Kode programnya sendiri ditulis pada Text Editor Sublime Text 3 dan menggunakan terminal Linux untuk me-execute atau menjalankan program tersebut. Proses yang dilakukan oleh program meliputi dua buah proses yaitu Face Detection dan Face Recognition. Kedua-nya sama-sama menggunakan proses training dari sebuah file xml yaitu Haarcascade Classifier yang tujuannya yaitu untuk mendeteksi dan menemukan bagian gambar yang dideteksi sebagai wajah atau letak citra wajah dalam sebuah gambar yang diuji. Di dalam Face Recognition proses training haarcascade tersebut digabungkan dengan proses training dari database citra wajah atau gambar yang ada di dalam database citra wajah agar sistem bisa mendeteksi dan mengenali wajah dari orang tersebut.
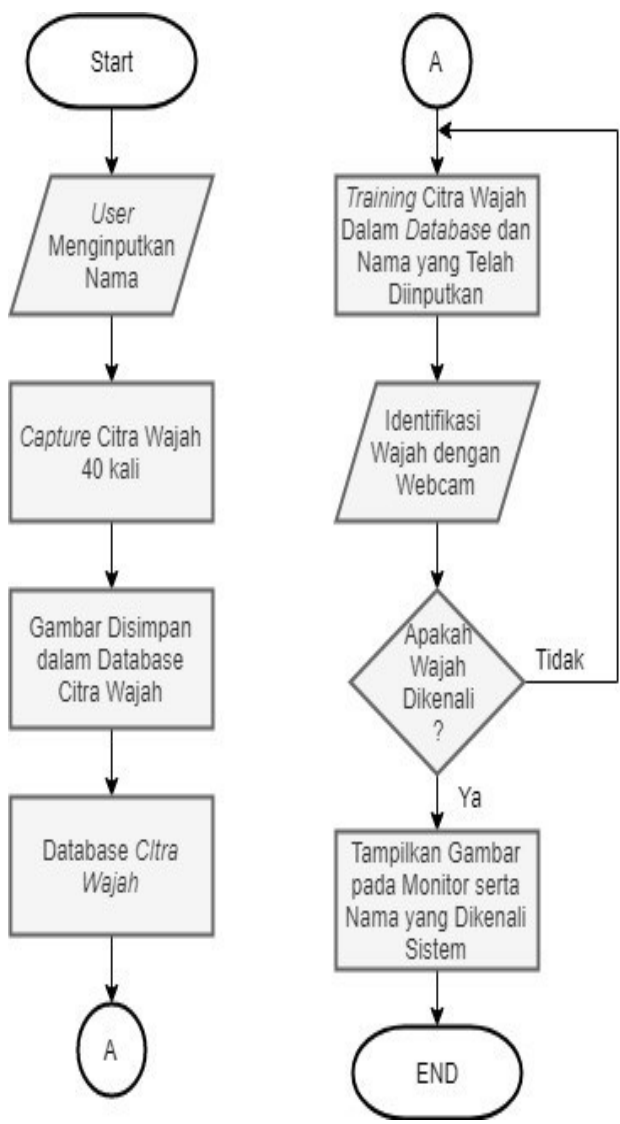

Gambar 6 Flowchart Sistem Face Recognition

Pengujian alat "Sistem Presensi Berbasis Face Recogntion" dilakukan untuk menguji apakah sistem dapat melakukan pengenalan pada wajah mahasiswa dengan akurasi yang tinggi serta 
bekerja sesuai dengan algoritma dan flow chart yang telah dirancang. Penguiian dilakukan berdasarkan faktor-faktor yang mempengaruhi dalam pengenalan seperti jumlah sampel gambar yang di-training, jarak webcam terhadap wajah dan jumlah intensitas cahaya. Oleh karena faktor-faktor tersebut, dilakukan 3 tahap pengujian untuk mendapatkan hasil pengenalan paling baik yaitu pertama pengujian jumlah sampel yang di-training terhadap persentase hasil pengenalan, kedua variasi jarak webcam terhadap wajah dan yang terakhir pengujian jumlah intensitas cahaya terhadap hasil pengenalan.

Adapun pengujian dilaksanakan pada 10 orang mahasiswa yaitu:

1. Mahasiswa 1 - Ahkmal Jenar Darmahendra (EC6B)

2. Mahasiswa 2 - Faris Abdul Azis (EC6B)

3. Mahasiswa 3 - Gabriel Alvino (EC6B)

4. Mahasiswa 4 - Habiburrahman (EC6B)

5. Mahasiswa 5 - Ichsan Kurniawan (EC6B)

6. Mahasiswa 6 - M Jamil Akmal (EC6B)

7. Mahasiswa 7 - Moch Fadli Rahmadi (EC6B)

8. Mahasiswa 8 - Mutia Shafira Chairunisa (EC6B)

9. Mahasiswa 9 - Pramita Retno Ayuning Tyas (EC6B)

10. Mahasiswa 10 - Tri Irfan (EC6B)

\section{HASIL DAN PEMBAHASAN}

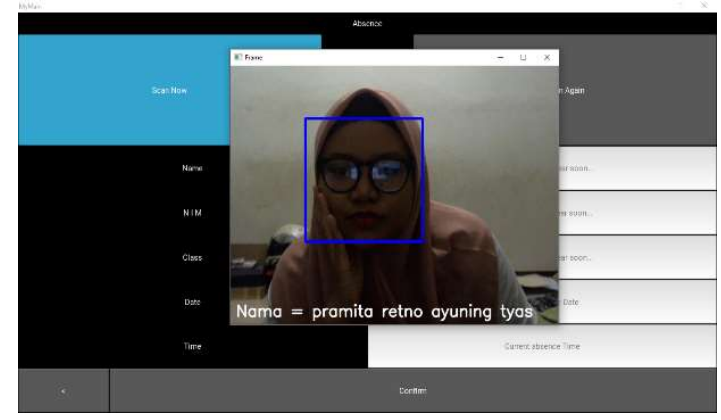

Gambar 7 Face Recognition pada Mahasiswa

\section{Jumlah Sampel Gambar yang Di-training}

Dari data hasil pengujian jumlah sampel gambar yang di-training terhadap hasil pengujian diperoleh:
- Untuk jumlah sampel 10 didapatkan data dengan wajah teridentfikasi atau dikenali sebanyak 2 dari 10 mahasiswa

- Untuk jumlah sampel 20 didapatkan data dengan wajah teridentfikasi atau dikenali sebanyak 5 dari 10 mahasiswa

- Untuk jumlah sampel 30 didapatkan data dengan wajah teridentfikasi atau dikenali sebanyak 8 dari 10 mahasiswa

- Untuk jumlah sampel 40 didapatkan data dengan wajah teridentfikasi atau dikenali sebanyak 10 dari 10 mahasiswa

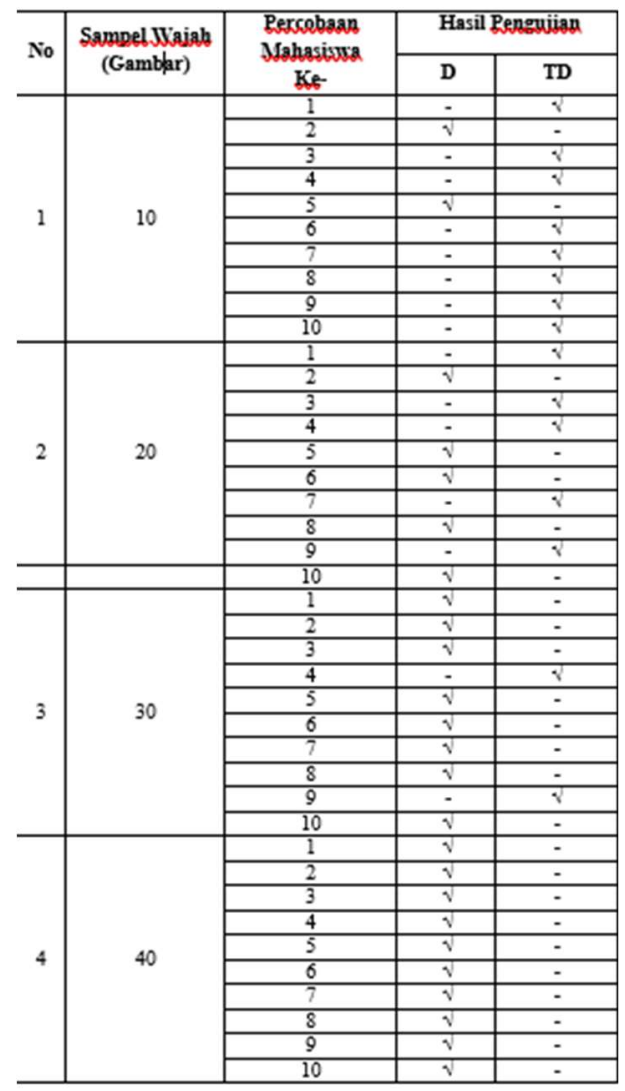

Gambar 8 Data Pengujian Jumlah Sampel Gambar yang di-training 


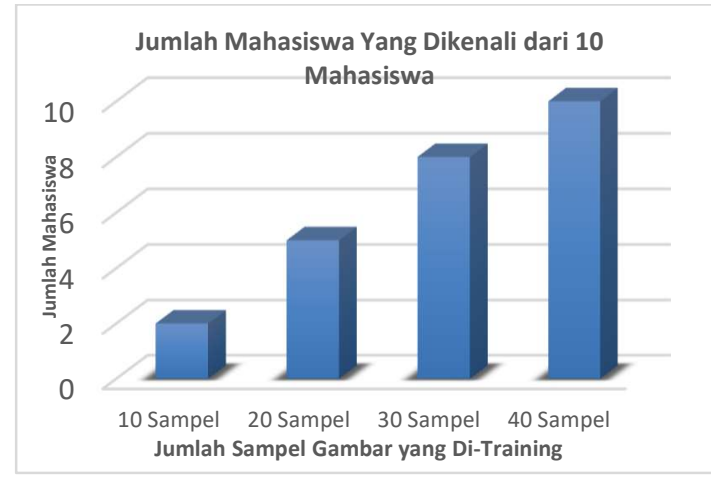

Gambar 9 Grafik Pengujian Jumlah Sampel Gambar yang di-training

2 Pengujian Jarak Webcam ke Wajah

Dari data hasil pengujian variasi jarak antara webcam dengan wajah terhadap hasil pengenalan diperoleh:

- Untuk jarak 10 - 29 cm didapatkan data dengan wajah teridentfikasi atau dikenali sebanyak 4 dari 10 mahasiswa

- Untuk jarak 30 - $59 \mathrm{~cm}$ didapatkan data dengan wajah teridentfikasi atau dikenali sebanyak 10 dari 10 mahasiswa

- Untuk jarak 60 - $89 \mathrm{~cm}$ didapatkan data dengan wajah teridentfikasi atau dikenali sebanyak 9 dari 10 mahasiswa

- Untuk jarak 90 - $129 \mathrm{~cm}$ didapatkan data dengan wajah teridentfikasi atau dikenali sebanyak 6 dari 10 mahasiswa

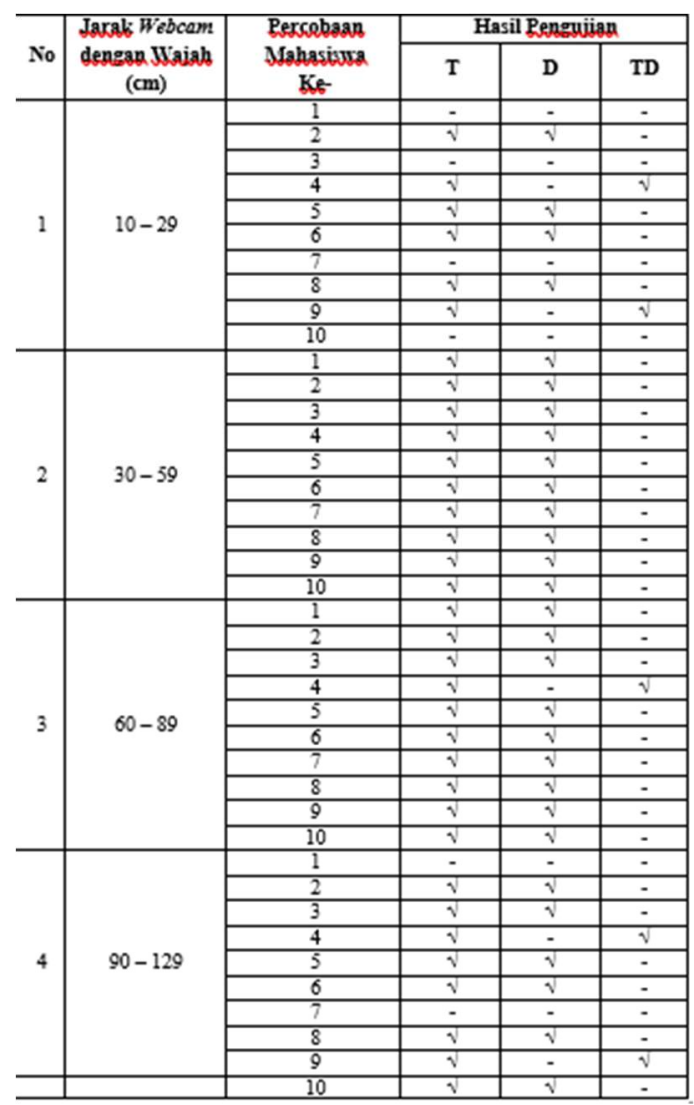

Gambar 10 Pengujian Variasi Jarak Webcam dengan Wajah

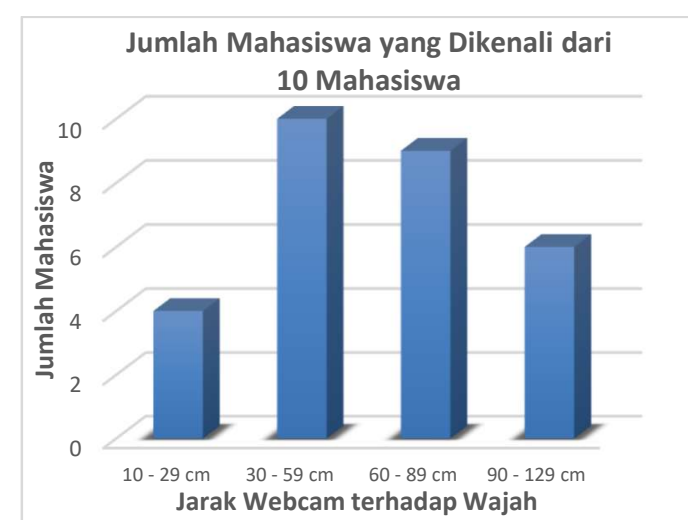

Gambar 11 Grafik Pengujian Variasi Jarak Webcam dengan Wajah 


\section{Pengujian Intensitas Cahaya}

Dari data hasil pengujian intensitas cahaya terhadap hasil pengenalan diperoleh:

- Untuk jarak 400 - 599 lux didapatkan data dengan wajah teridentfikasi atau dikenali sebanyak 4 dari 10 mahasiswa

- $\quad$ Untuk jarak 600 - 799 lux didapatkan data dengan wajah teridentfikasi atau dikenali sebanyak 5 dari 10 mahasiswa

- Untuk jarak 800 - 999 lux didapatkan data dengan wajah teridentfikasi atau dikenali sebanyak 10 dari 10 mahasiswa

- Untuk jarak 1000 - 1500 lux didapatkan data dengan wajah teridentfikasi atau dikenali sebanyak 7 dari 10 mahasiswa

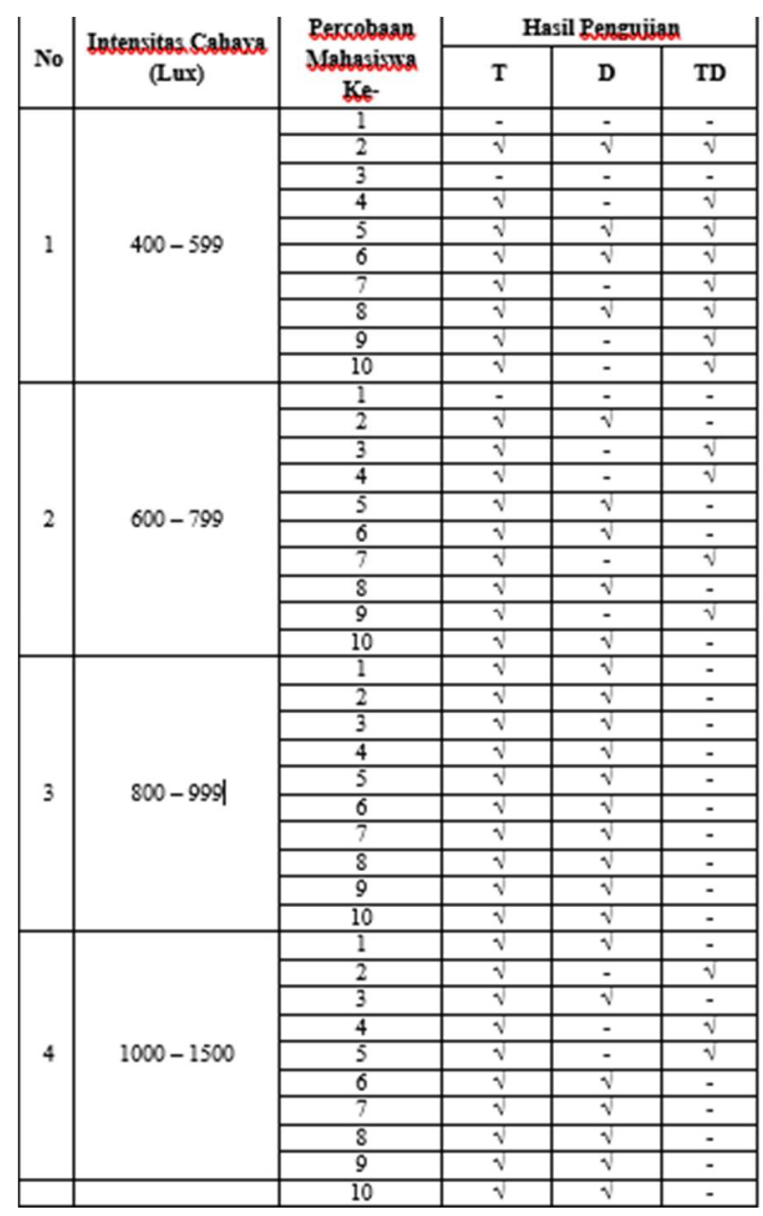

Gambar 12 Pengujian Intensitas Cahaya

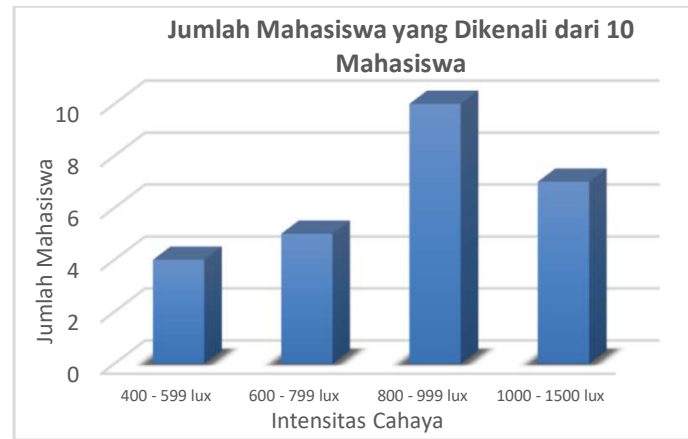

Gambar 13 Grafik Pengujian Intensitas Cahaya Terhadap Hasil Pengenalan

\section{KESIMPULAN}

Berdasarkan perancangan, realisasi data hasil pengukuran dan analisa data untuk melakukan pengenalan wajah (face recognition) dengan menggunakan kamera Logitech seri C525 dapat di simpulkan bahwa:

1. Jumlah sampel gambar yang di-training sehingga dapat menghasilkan pengenalan pada wajah paling akurat saat melakukan proses absen adalah sebenyak 40 sampel.

2. Jarak $30-59 \mathrm{~cm}$ antara webcam dengan wajah merupakan jarak terbaik saat melakukan proses absensi dengan pengenalan pada wajah.

3. Intensitas cahaya yang paling baik pada saat proses absen berkisar 800-999 lux dalam menghasilkan pengenalan wajah yang paling akurat.

\section{UCAPAN TERIMAKASIH}

Terima kasih kepada Politeknik Negeri Jakarta untuk mendanai peneletian ini, dan juga untuk dosen pembimbing Nuralam,S.T.,M.T.

\section{DAFTAR PUSTAKA}

[1] Reski Kiki, R, Rahmansyah, Ady, \& Darwin, Wahyuni. 6 Juli 2017. Penggunaan Bahasa Pemrograman Python Sebagai Pusat Kendali Pada Robot 10-D. 5th Indonesian Symposium on Robotic Systems and Control. ISBN: 978-60272004-3-2 
[2] Kapele Priska, F. C. 29 Mei 2014. Makalah Sistem Operasi (Linux Ubuntu). Manado: Universitas Negeri Manado.

[3] Nathanael, Ryan \& Oktian, Yutus Eko. 21 Juni 2012. Face Recognition Dengan Menggunakan Eigenface. https://uniknown.wordpress.com/2012/06/ 21/face-recognitiondengan-menggunakaneigenface/

[4] D. A. Prasetya and I. Nurviyanto, "Deteksi wajah metode viola jones pada opencv menggunakan pemrograman python," Simp. Nas. RAPI XI FT UMS, pp. 18-23, 2012.

\section{Gambar Alat}

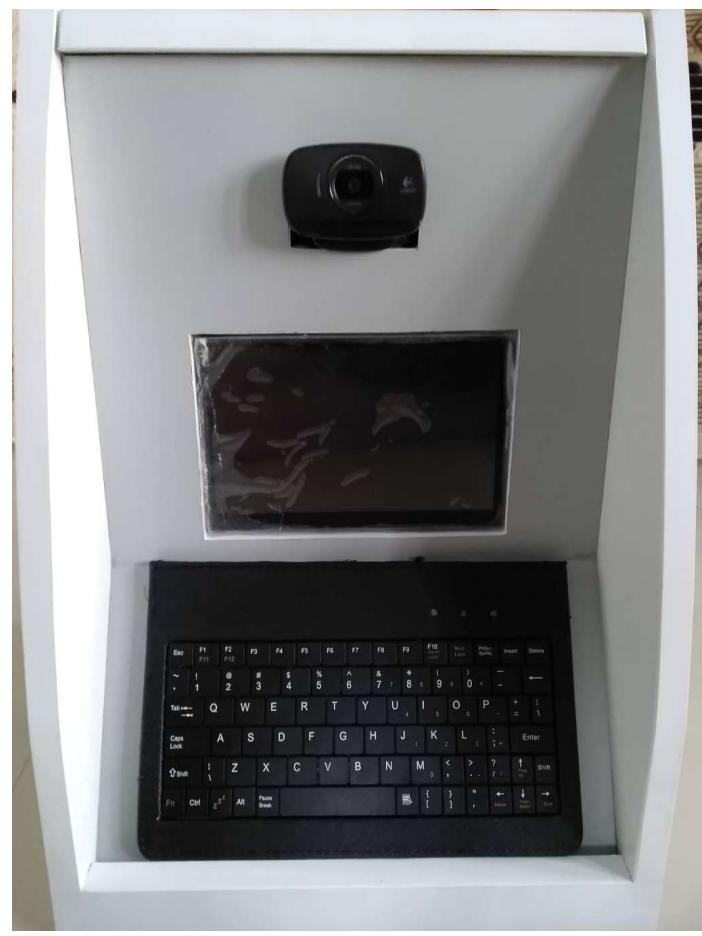

Gambar 14 Mesin Presensi Berbasis Face Recognition 